\title{
humanidades
}

Revista humanidades

Enero-junio, 2016 • Volumen 6, número 1 • ISSN 2215-3934 • pp. 1-12

\section{La escuela y las nuevas formas de convivencia}

DOI: http://dx.doi.org/10.15517/h.v6i1.24962

\section{Miguel Ángel Estrada}

Doctor en Ciencias de la Educación. Académico en la Escuela Normal Rural "J.

Guadalupe Aguilera", México.

Correo electrónico: m.angel_estrada@yahoo.com

Todos los derechos reservados. Universidad de Costa Rica. Esta revista se encuentra licenciada con Creative Commons Reconocimiento-NoComercial-SinObraDerivada 3.0 Costa Rica.

Correo electrónico: humanidades@ucr.ac.cr / Sitio web: http://revistas.ucr.ac.cr/index.php/humanidades 


\section{La escuela y las nuevas formas de convivencia}

\section{Resumen}

Actualmente, en las escuelas aumenta la reproducción de dinámicas de convivencia negativas, las cuales están siendo consideradas como nuevas, aunque siempre han estado presentes, esto se debe a que se trata de un tema que recientemente retomó importancia. Dentro de las principales manifestaciones se encuentra el acoso escolar, en todas sus modalidades: mobbing, bullying, acoso del docente al alumno y acoso del alumno al docente. Algunos de los detonantes del citado fenómeno son el ambiente y el clima escolar.

\section{The School and the Forms new of Convivence}

Palabras clave: Convivencia, ambiente escolar, acoso escolar, matonismo, violencia escolar.
Keywords: Convivence, ambience, climate, harassment scholar, school bullying. 
La convivencia escolar es un tema recurrente en los estudios académicos; no obstante, actualmente ha cobrado interés puesto que mundialmente han Introducción surgido "nuevas formas de convivencia", las cuales provocan el fenómeno del acoso escolar. Lo anterior ha ocasionado grandes problemas, algunos relacionados con el proceso de enseñanza-aprendizaje y otros mucho más graves, donde incluso aparece el suicidio. En ese tenor, autoridades educativas, investigadores, docentes y otros actores educativos y sociales, han diseñado e implementado protocolos de convivencia, con el objetivo de eliminar la violencia escolar, principalmente la que acontece entre los alumnos y que en ocasiones llega a convertirse en bullying o acoso escolar.

Antes de abordar las nuevas dinámicas de convivencia escolar, es necesario aclarar varios conceptos. El primero es convivencia, vocablo que se define, de acuerdo con la Real Academia Española (2014), como "la acción de convivir", es decir, el vivir en compañía de otros. En ese sentido, Coronado (2008) afirma que convivir es "compartir espacios y recursos, en un tiempo determinado. Espacios físicos, simbólicos y sociales” (p. 86). Así pues, la escuela representa los tres tipos de espacio a la vez: el físico, lo representa la infraestructura que integra el edificio escolar; el simbólico, se refiere al significado o valor que se le da a la escuela y cada parte de esta (dirección, aulas, biblioteca, etc.); y, al ser la escuela un lugar en el que convergen y conviven muchos individuos, se convierte en un espacio social.

Las características o condiciones de los espacios mencionados en el párrafo anterior determinan el ambiente escolar. Duarte (2003) sostiene que "el ambiente es concebido como el conjunto de factores internos biológicos y químicos y externos físicos y psicosociales que favorecen o dificultan la interacción social" (s. p.). 
Cuando se hace referencia a que el ambiente favorece la interacción entre individuos o a que la limita, se puede inferir que pueden existir ambientes positivos o negativos; por consiguiente, la convivencia que se presente puede ser sana o perjudicial para los actores educativos. Asimismo, al estar condicionado el ambiente a factores internos (biológicos y químicos) y externos (físicos y psicosociales), se hace referencia a que el ambiente estará condicionado por la cultura, el tiempo y el entorno. En ese sentido, se puede afirmar que el ambiente social cambia la forma de ser y de actuar de las personas, pero también las personas pueden cambiar o modificar su ambiente social.

García (1991) afirma que la influencia de los individuos en el ambiente inicia, se refuerza o se debilita, de acuerdo con la conducta continuada que se manifiesta en actos similares repetidos constantemente, es decir, con hábitos. Asimismo, el ambiente escolar determina el clima institucional, Rodríguez (2004) define el clima escolar de la siguiente manera:

El conjunto de características psicosociales de un centro educativo, determinado por todos aquellos factores o elementos estructurales, personales y funcionales de la institución que, integrados en un proceso dinámico específico confieren un peculiar estilo o tono a la institución, condicionante, a su vez, de los distintos productos educativos (pp. 1-2).

Hacer referencia a las características psicosociales es hablar de las relaciones entre personas y de cómo las llevan a cabo. También se trata de los efectos que estas producen en su formación y desarrollo; por consiguiente, de la influencia que tienen en su forma de ser o de actuar. Silva (2004) afirma que el clima escolar es resultado de la identidad escolar 
y de la calidad de las interacciones personales, lo cual conforma en gran parte los procesos y resultados del centro educativo.

Con lo abordado hasta el momento, se puede establecer que los tipos de convivencia escolar pueden ser positivos o negativos, según el impacto que tengan en el desarrollo humano de los actores educativos; además, que están determinados de acuerdo con el ambiente y el clima de la escuela.

Regularmente la convivencia se asocia con valores como el respeto, la tolerancia, equidad, igualdad, etc., es decir, se relaciona con algo positivo o idóneo, derivado de la interacción de los individuos. Así, se deja de lado que en toda relación humana siempre van a existir conflictos, los cuales en ocasiones no son resueltos a través del diálogo o negociación, sino a través de la fuerza o la violencia, lo cual genera una convivencia negativa.

La convivencia escolar negativa se presenta por medio de la violencia y acoso escolar. La violencia escolar es definida por el Centro Reina Sofía (2005, citado por Valdivieso, 2009, p. 67) como "cualquier tipo de violencia que se da en contextos escolares. Puede ir dirigida hacia alumnos, profesores o propiedades".

Así las cosas, la violencia escolar es un fenómeno que siempre ha existido en los centros escolares, pero que en la actualidad está causando más estragos. Dicha situación se debe también a la cultura de la sociedad actual, puesto que está insensibilizada ante la violencia, lo que trae como consecuencia que algunas "nuevas formas de convivencia escolar" se centren en la violencia.

Las "nuevas formas de convivencia" entre los actores educativos, a las que se hace referencia en este artículo, se representan básicamente en el acoso escolar. Este último es erróneamente conocido como sinónimo de bullying; 
sin embargo, el acoso escolar es un término más amplio, en tanto que el bullying o acoso entre alumnos es solo un tipo de acoso escolar.

El acoso escolar se debe entender como la conducta agresiva, repetida, intencional y por un periodo de tiempo, que ejecuta un actor educativo hacia otro (o hacia sus pertenencias y posesiones).; a través de actos de agresión física, verbal y psicológica. Para dejar más clara la definición anterior, es necesario especificar que cuando se habla de actor educativo, este puede ser director, docente, alumno, intendente, secretaria, etc., en sí cualquier persona que desempeña un rol en el sector educativo. En ese tenor, el agresor o víctima puede ser cualquiera de ellos, incluso, en ocasiones puede desempeñar ambos roles.

Existen cuatro tipos de acoso escolar (Tabla 1).

Tabla 1

Tipos de acoso escolar

Nombre Principales Actores

Mobbing escolar o acoso laboral Dos o más trabajadores

Bullying o acoso entre alumnos Dos o más alumnos

Acoso del docente hacia el alumno Docente y alumno

Acoso del alumno hacia el docente Alumno y docente

Fuente: Creación propia 
El mobbing o acoso laboral ha sido investigado principalmente en las empresas, Piñuel lo define como:

El continuo y deliberado maltrato verbal y modal que recibe un trabajador por parte de otro $\mathrm{u}$ otros, que se comportan con él cruelmente con vistas a lograr su aniquilación o destrucción psicológica y a obtener su salida de la organización a través de diferentes procedimientos (2001, p. 52).

Centrando la definición en el ámbito educativo, se puede afirmar que el mobbing escolar se presenta cuando un trabajador, ya sea docente, administrativo o de servicios, agrede física, verbal o psicológicamente a otro trabajador (o a las posesiones de este). Lo anterior debe acontecer por un periodo de tiempo y tiene que existir la intención de causar un daño físico, psicológico o económico.

El mobbing escolar, o acoso entre trabajadores de la educación, puede clasificarse en tres tipos: ascendente, descendente o lineal. El tipo depende del cargo o función que desempeñe el agresor, en la Figura 1 se pueden observar algunos ejemplos.
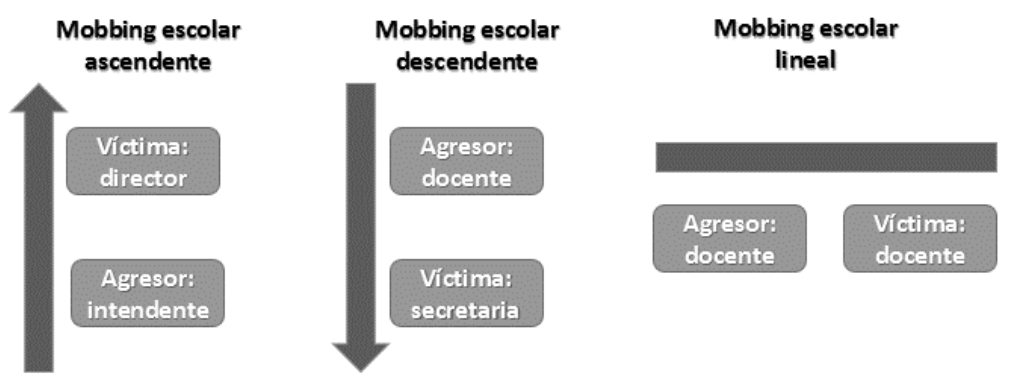

Figura 1: Clasificación del mobbing escolar

Fuente: Elaboración propia 
El bullying, o acoso entre alumnos, es el tipo de acoso escolar que mayormente se ha investigado. Olweus lo define de la siguiente manera:

Es una conducta de persecución física o psicológica que realiza el alumno o alumna contra otro, al que elige como víctima de repetidos ataques. Esta acción, sitúa a las víctimas en posiciones de las que difícilmente puede salir por sus propios medios. La continuidad de estas relaciones provoca en las víctimas efecto claramente negativos: descenso en su autoestima, estados de ansiedad e incluso cuadros depresivos, lo que dificulta su integración en el medio escolar y el desarrollo normal de los aprendizajes (1983, citado por Castro, 2007, p. 72).

En México, el acoso entre alumnos es un problema grave. Al respecto, Bolaños (2011) escribió un artículo en el periódico El Universal con el encabezado "Hubo 190 suicidios por bullying en 2010". En dicha publicación, se menciona que durante una entrevista realizada a la directora de la asociación Fundación en Movimiento, ella expresó que en el 2010 se registraron 190 suicidios a causa del bullying.

Otro tipo de acoso escolar surge cuando el docente es acosador y el alumno el acosado. Esta forma de acoso se presenta a través de una conducta agresiva, repetida e intencional, la cual ejecuta un docente hacia un alumno (o hacia las pertenencias y posesiones de este); por medio de actos de agresión física, verbal y psicológica.

Esta modalidad de acoso puede ser la más difícil de detectar, ya que en ocasiones el docente, con la intención de mantener orden y disciplina en el salón de clase, lleva a cabo "castigos" constantemente. Por lo general, los alumnos que alteran el orden o el ambiente son los mismos, estos reciben más castigos, además, están etiquetados como alumnos problema; en ese 
sentido, puede ser que el docente frecuentemente los ponga en evidencia con el resto del grupo o con otros docentes.

Por lo anterior, el alumno "problema" se siente agredido y tiende a desarrollar conductas negativas de manera frecuente, hasta convertirlas en hábitos. Dicha situación se puede convertir en un círculo vicioso, tal y como se ilustra en la Figura 2.
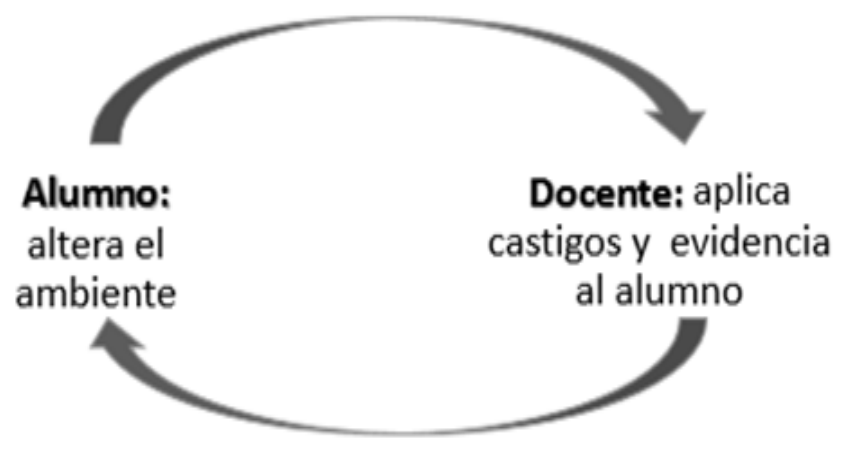

Figura 2: Dinámica docente acosador

Fuente: Elaboración propia

Cabe mencionar que el acoso no se presenta por el hecho de aplicar el castigo al alumno como medida correctiva, sino al momento ponerlo en evidencia de manera constante con otros actores educativos. No obstante, también puede presentarse por el hecho de estar recibiendo castigos que en ocasiones no son justificados, ya que por presentar conductas inadecuadas de manera frecuente podría convertirse en "chivo expiatorio".

La última forma de acoso escolar es la que acontece por parte de uno o más alumnos hacia un docente. Esta se puede definir como una la conducta 
agresiva, repetida e intencional que ejecuta un alumno hacia un docente (o hacia las pertenencias y posesiones de este); a través de actos de agresión física, verbal y psicológica.

Los profesores más vulnerables a ser acosados son los noveles o los de edad muy avanzada. Los primeros, por causa de su inexperiencia, pueden carecer de estrategias y dinámicas para abordar contenidos, mostrar nerviosismo frente al grupo, no dominar contenidos, etc. Lo anterior puede provocar burlas y desacreditación por parte de los alumnos. Los docentes de edad avanzada pueden ser acosados por ese simple hecho, pues el aspecto de adulto mayor o la manera de hablar pueden ser objeto de burla $\mathrm{y}$ de apodos por parte de sus alumnos.

En conclusión, los tipos de acoso escolar se conocen actualmente como "nuevas formas o dinámicas de convivencia", puesto que se trata de un tema que recientemente retomó importancia. A causa de las investigaciones realizadas y de los resultados obtenidos, que han sido graves, se ha buscado, a través de diferentes estrategias implementas por padres, investigadores, organizaciones, dependencias gubernamentales, etc., que la convivencia entre los actores educativos sea positiva o sana.

Coronado (2008) afirma que "para construir una convivencia sana [cursivas añadidas] es fundamental partir de la aceptación de que el conflicto es inevitable, porque solamente cuando se enfrentan y aprovechan las tensiones y confrontaciones propias del convivir es posible instaurar procesos de construcción escolar pacífica” (p. 12). 
Bolaños, C. (22 de febrero de 2011). Hubo 190 suicidios por bullying en 2010. El Universal. Recuperado de http://www.eluniversal.com.mx/notas/746856.html

Castro, A. (2007). Violencia silenciosa en la escuela. Buenos Aires, Argentina: Bonum.

Coronado, M. (2008). Competencias sociales y convivencia: herramientas de análisis y proyectos de interveción. Buenos Aires, Argentina: Ediciones Novedades Educativas.

Duarte, J. (2003). Ambientes de aprendizaje. Una aproximación conceptual, 27 (st) . En Estudios pedagógicos, pp. 97-113. Recuperado de http://www.scielo.cl/scielo.php?script=sci_arttext\&pid=S071807052003000100007

García, V. (1991). Ambiente, organización y diseño educativo. Madrid, España: Gráficas Rógar, S.A.

Piñuel, I. (2001). Cómo sobrevivir al acoso psicológico en el trabajo. España: Salterrae.

Real Academia Española. (2012). Diccionario de la lengua española (22. ${ }^{\mathrm{a} e d}$.). Madrid, España: Autor. Consultado en http://www.rae.es/rae.html

Rodríguez, N. (2004). El clima escolar. En Investigación y educación, 7 (1), sp. Recuperado de: http://www.csif.es/archivos_migracion_estructura/andalucia/modules/mod_sevil la/archivos/revistaense/n7v3/clima.PDF

Silva, O. (2004). Gestión de la educación y el clima organizacional. En Ansión, J. \& Villacorta, Ana (Eds.). Para comprender la escuela pública desde sus crisis y posibilidades (pp. 277-296) . Perú:

Pontificia Universidad Católica del Perú. 
Valdivieso, P. (2009). Violencia escolar y relaciones intergrupales. Sus prácticas y significados en las escuelas secundarias públicas de la comuna de Peñalolen en Santiago de Chile (Tesis doctoral) . Recuperado de http://www.ugr.es/ erivera/PaginaDocencia/Posgrado/Document os/ValdiviesoPablo.pdf.

Recibido: 29-octubre-2015

Aceptado: 11-febrero-2016

Todos los derechos reservados. Universidad de Costa Rica. Esta revista se encuentra licenciada con Creative Commons Reconocimiento-NoComercialSinObraDerivada 3.0 Costa Rica. (CC BY-NC-SA 3.0 CR)

Correo electrónico: humanidades@ucr.ac.cr Sitio web: http://revistas.ucr.ac.cr/index.php/humanidades 